\title{
Apresentação Matemática nos Anos Iniciais
}

\author{
Reginaldo Fernando Carneiro' \\ Cármen Lúcia Brancaglion Passos"
}

'Universidade Federal de Juiz de Fora (UFJF), Juiz de Fora/MG - Brasil

"Universidade Federal de São Carlos (UFSCar), São Carlos/SP - Brasil

A formação do professor nos cursos de Licenciatura em Pedagogia tem sido foco de questionamentos, discussões e debates no campo educacional, devido à diversidade de habilitações que proporciona ao futuro profissional.

O pedagogo é formado para atuar na Educação Infantil, nos anos iniciais do Ensino Fundamental e também na Educação de Jovens e Adultos, por isso, contempla uma gama de conhecimentos relativos às diversas disciplinas presentes no currículo escolar, como: Geografia, Língua Portuguesa, História, Ciências, Matemática etc., além das referentes às outras habilitações. Alguns cursos de Pedagogia também habilitam o profissional para atuar na orientação, na supervisão e na administração escolar. Essas atribuições não são determinadas pelas instituições de formação, visto que a Resolução CNE/CP n. 1/06 (Brasil, 2006, art. $4^{\circ}$, online) indica que o curso de Licenciatura em Pedagogia se destina à formação de professores para,

\begin{abstract}
[...] exercer funções de magistério na Educação Infantil, nos anos iniciais do Ensino Fundamental, nos cursos de Ensino Médio, na modalidade Normal, de Educação Profissional na área de serviços e apoio escolar e em outras áreas nas quais sejam previstos conhecimentos pedagógicos.
\end{abstract}

Essa mesma resolução também institui a carga horária dos cursos de Pedagogia e exige o mínimo de 3.200 horas. Algumas Instituições de Ensino Superior transformam esse mínimo, previsto na lei, em máximo, nos seus cursos de formação inicial.

Nesse contexto, colocamos algumas inquietações: como formar um profissional para atuar em todas essas áreas? A pretensão de capacitar um profissional para todas essas habilitações não proporcionaria uma formação aligeirada e superficial, diminuindo sua qualidade? E, no que se refere à matemática, como é a formação desse docente? Quais conteúdos e metodologias são abordados nesses cursos? Como é essa abordagem?

Educação \& Realidade, Porto Alegre, v. 39, n. 4, p. 977-984, out./dez. 2014.

Disponível em: <http://www.ufrgs.br/edu_realidade> 
Apresentação da Seção Temática - Matemática nos Anos Iniciais

De acordo com Gatti (2010), as inúmeras funções que podem ser desempenhadas pelo pedagogo determinam a complexidade curricular do curso de Pedagogia, que deve englobar disciplinas para atender a todas elas, com tempo e carga horária específicos, o que se torna ainda mais difícil, quando se pensa nos cursos noturnos.

Em seu estudo, a autora tomou como amostra 71 cursos de Pedagogia distribuídos por todos os estados brasileiros, por categoria administrativa (privada - particular ou comunitária confessional - e pública - municipal, estadual ou federal) e por organização acadêmica (universidade, centro universitário, faculdade, faculdades integradas ou institutos superiores de educação), e verificou que apenas 0,6\% das disciplinas se referem à profissão docente e enfatizam os aspectos teóricos, deixando em segundo plano a prática educacional. Para Gatti (2010), as disciplinas que compõem esse grupo se preocupam em justificar o porquê de ensinar e muito pouco o que e como ensinar.

Além disso, 7,5\% das disciplinas dos cursos referem-se aos conteúdos que os formados ensinarão nos anos iniciais. Gatti (2010, p. 1.368 e p. 1.372) ressalta que "[...] esse dado torna evidente como os conteúdos específicos das disciplinas a serem ministradas em sala de aula não são objeto dos cursos de formação inicial do professor" e que disciplinas com o objetivo de abordar os conteúdos específicos a serem ensinados aparecem “[...] esporadicamente nos cursos de formação e, na grande maioria dos cursos analisados, eles são abordados de forma genérica ou superficial, sugerindo frágil associação com as práticas docentes”.

Nesse contexto, diversas pesquisas (Batista; Lanner, 2007; Curi, 2005; Nacarato, 2010; Nacarato; Mengali; Passos, 2009; Passos, 2005) têm abordado diferentes aspectos da matemática na formação dos professores dos anos iniciais.

Em um levantamento, realizado por Batista e Lanner (2007), foram encontradas, no estado de São Paulo, 193 instituições que ofereciam cursos de Pedagogia. Do total de 316, contudo, apenas 55\% deles tinham em seus currículos disciplinas voltadas para a formação matemática e/ou estatística do futuro professor. Esses autores ainda destacam que não se pode afirmar que essas disciplinas tivessem como objetivo preparar os docentes para ensinar matemática ou estatística.

Na investigação de Curi (2005), evidenciou-se que as disciplinas específicas de matemática, quando oferecidas nos cursos de Pedagogia, têm uma carga horária muito reduzida, de 36 a 72 horas, o que equivale apenas a $4 \%$ da carga total do curso. Além disso, a mesma pesquisa ressaltou que as informações sobre os temas abordados nas disciplinas eram muito gerais como, por exemplo: “[...] estudo de métodos de ensino e aprendizagem para a construção de conhecimentos matemáticos, conteúdos, métodos, planejamento e avaliação, análise das teorias do conhecimento" (Curi, 2005, p. 6). Entre os conteúdos matemáticos abordados, o destaque era para a construção do número e as quatro 
operações; e muito raramente o ensino de geometria era indicado nas ementas.

Corroborando essa afirmação, Nacarato, Mengali e Passos (2009) destacam que os docentes desse nível de ensino, nos cursos de formação inicial, têm contato com aspectos metodológicos do ensino de matemática em disciplinas com carga horária bastante reduzida, e não há indicação de que vivenciem os fundamentos da matemática e a prática da pesquisa em educação matemática.

Dessa forma, a prática profissional desses docentes acaba por reproduzir a dos professores que eles tiveram durante sua vida escolar, que, de acordo com as autoras, têm forte influência na sua identidade e na constituição do seu modelo de aula. Via de regra, esses futuros professores tiveram um ensino de matemática pautado nas operações aritméticas a partir de algoritmos. Assim, a formação inicial deve possibilitar ao docente "[...] construir um currículo de matemática que transcenda o ensino de algoritmos e cálculos mecanizados, principalmente nos anos iniciais, onde está a base da alfabetização matemática”. Além disso, esses docentes demonstram "[...] trazer marcas profundas de sentimentos negativos em relação a essa disciplina, as quais implicam, muitas vezes, bloqueios para aprender e para ensinar" (Nacarato; Mengali; Passos, 2009, p. 32 e p. 23).

Nesse sentido, trechos de relatos de futuras professoras dos anos iniciais demonstram esses aspectos. Uma futura professora explicitou que pode representar seus "[...] sentimentos através do desenho de uma bomba que está prestes a explodir, porque na maioria das vezes levava bomba nas avaliações de matemática na escola". Outra licencianda comentou que "[...] por não conseguir entender, resolvi abandonar tentar entender e só cumprir as regras, foi um tanto frustrante, pois não tive sucesso" (Nacarato; Mengali; Passos, 2009, p. 28, grifo das autoras).

No estudo de Passos (2005), esse aspecto também foi evidenciado, indicando que muitos professores que atuam nesse nível de ensino têm dificuldades e, até mesmo, aversão à matemática e, com o intuito de não ter que estudar mais essa disciplina, procuram realizar cursos nas áreas das ciências humanas. Como afirma essa autora (2005, p. 31), em investigação realizada com alunos do curso de Magistério, "[...] a grande maioria dos alunos [...] não gostava de matemática e expressava aversão tão grande que chegava a afirmar que jamais ensinaria essa disciplina".

Nacarato (2010) indica que as dificuldades dos estudantes de Pedagogia estão nas marcas deixadas pela matemática durante sua vida escolar e nos bloqueios com relação à aprendizagem, o que gera conflitos, pois terão que ensinar essa disciplina. Diante desse cenário, a autora defende que a formação deve buscar romper com as crenças e com as culturas de aulas de matemática que os futuros professores vivenciaram durante toda sua trajetória escolar. Para tanto, é necessário que essas marcas sejam explicitadas e discutidas durante a formação. 
Apresentação da Seção Temática - Matemática nos Anos Iniciais

Dessa forma, a autora (2010) apresenta algumas discussões a partir do que ela denomina a escrita de si: relatos autobiográficos e textos reflexivos escritos pelas alunas do curso de Pedagogia, em que elas narram conteúdos matemáticos de que gostavam ou que não aprenderam nas aulas e também fatos sobre os professores dessa disciplina. Foram destacadas lembranças sobre a aritmética e, com menos ênfase, sobre a geometria, e ainda aspectos utilitaristas da matemática. Além disso, as lembranças sobre sua trajetória escolar possibilitaram discussões sobre o ensino de matemática no Brasil, marcado, nos anos de 1960 e 1970, pela tendência tecnicista e formalista moderna. Pelo fato de as participantes desse estudo terem em torno de 20 a 25 anos, a autora vê indícios de que as reformas pouco influenciaram o ensino dessa disciplina.

Nessa perspectiva, as frustrações, as inseguranças e os medos, relacionados à matemática ensinada no processo de escolarização dessas futuras professoras, poderão repercutir na configuração de suas aulas para alunos dos anos iniciais de escolarização. Daí a relevância da formação inicial dessas professoras. Nacarato, Mengali e Passos (2009, p. 37-38) apontam que,

[...] o desafio consiste em criar contextos em que as crenças que essas professoras foram construindo ao longo da escolarização possam ser problematizadas e colocadas em reflexão, mas, ao mesmo tempo, que possam tomar contato com os fundamentos da matemática de forma integrada às questões pedagógicas.

A partir desse contexto, evidenciado pelas pesquisas apresentadas, o artigo de Carneiro, Passos e Lupiáñez (2012), A Formação Matemática de Professores da Educação Primária na Espanha: contribuições para a realidade brasileira, apontou alguns caminhos que podem levar a reflexões sobre o curso que forma o professor que atua nos anos iniciais do Ensino Fundamental. Os autores investigaram como ocorre a formação do professor que ensina matemática nos anos iniciais no curso da Universidade de Granada - Espanha -, e depararam-se com quatro disciplinas referentes à matemática, três delas obrigatórias e com carga horária significativa. Devido às recentes mudanças curriculares ocorridas no curso, propostas pelo processo de Bolonha ${ }^{1}$, apenas duas das disciplinas relacionadas à matemática já haviam sido desenvolvidas com os estudantes, no primeiro semestre de 2012, período de desenvolvimento da pesquisa.

Essa quantidade de disciplinas evidencia a importância dos conteúdos matemáticos e também dos processos de ensinar e aprender matemática. A primeira disciplina do curso, denominada Bases Matemáticas para la Educación Primaria, aborda os conteúdos matemáticos trabalhados nos anos iniciais, na perspectiva do ensino e da aprendizagem, em que se focam, por exemplo, a resolução e a formulação de problemas, a justificativa dos algoritmos tradicionais das operações, as explorações e as investigações, entre outros. 
O objetivo da disciplina Enseñanza y aprendizaje de las matemáticas en la Educación Primaria é abordar os fundamentos da didática da matemática, o processo de ensino e aprendizagem nos anos iniciais e também os conteúdos matemáticos. Nessa disciplina discutem-se: o papel da matemática no sistema educativo e no currículo; os conceitos básicos da didática da matemática, relativos aos sentidos numérico, espacial, medida e do pensamento aleatório; os processos de aprendizagem da matemática etc.

Um dos aspectos que permite esse número de disciplinas é o fato de o curso de formação de professores habilitar apenas para atuar nos anos iniciais do Ensino Fundamental. Essa é uma alternativa para melhorar a formação matemática dos professores, pois apenas com uma habilitação é possível acrescentar disciplinas referentes aos conteúdos que devem ser ensinados nesse nível de ensino, diferentemente do que indicam as pesquisas sobre os cursos brasileiros de Pedagogia, que apresentam poucas disciplinas com esse intuito e oferecem cargas horárias reduzidas.

Além disso, os alunos do curso de formação de professores da Universidade de Granada desenvolvem atividades relacionadas ao ensino e à aprendizagem da matemática nos seminários de prática, que fazem parte de todas as disciplinas. Nesses seminários, os estudantes participam de atividades práticas relacionadas com o que foi discutido nas aulas teóricas, tiram dúvidas etc. E ainda têm a tutoria individualizada, na qual são atendidos pelo docente de forma personalizada, em busca de resolver as dificuldades verificadas sobre os temas estudados e sobre as tarefas que devem realizar.

Somam-se a isso as diferentes abordagens e articulações apresentadas nas duas disciplinas acompanhadas durante o estágio, que abordam os fundamentos da matemática a partir da resolução de problemas, da justificativa e da compreensão dos processos matemáticos, pois, segundo os autores também explicitaram, a presença de disciplinas não implica necessariamente uma melhor formação: é necessário também articular a maneira como são trabalhados os conteúdos matemáticos.

A partir desse complexo cenário, que aponta ainda haver muitas lacunas nessa formação, compusemos esta seção temática, com o objetivo de trazer contribuições para o debate, a partir das investigações de pesquisadores da Educação Matemática que se preocupam com a formação do professor que ensina matemática nos anos iniciais do Ensino Fundamental.

Os artigos que compõem este número da Revista Educação \& Realidade abordam diferentes aspectos dessa formação. Os quatro primeiros textos têm como foco professores que já atuam no ensino de matemática nos anos iniciais.

Regina Célia Grando, Adair Mendes Nacarato e Celi Espasandin Lopes assinam o artigo intitulado Narrativa de Aula de uma Professora 
Apresentação da Seção Temática - Matemática nos Anos Iniciais

sobre a Investigação Estatística, no qual analisam a narrativa de aula de uma professora, com o intuito de investigar os letramentos matemáticos escolares e as práticas de formação docente de professores que ensinam Matemática. Essa narrativa descreve o processo de investigação estatística desenvolvido com uma turma de $1^{\circ}$ ano.

$\mathrm{O}$ artigo O Movimento de Formação Docente no Ensino de Geometria nos Anos Iniciais, de Anemari Roesler Luersen Vieira Lopes e Halana Garcez Borowsky Vaz, investigou a formação de professores que ensinam matemática nos anos iniciais, ao planejarem, desenvolverem e avaliarem uma atividade orientadora de ensino de geometria.

Aciepe Histórias Infantis e Matemática: uma instância formativa, artigo de autoria de Ana Paula Gestoso de Souza e Rosa Maria Moraes Anunciato de Oliveira, apresenta e discute, a partir da trajetória de cinco egressas do curso de Pedagogia, a dinâmica dessa Aciepe - Atividade Curricular de Integração Ensino Pesquisa e Extensão -, que se mostrou uma instância formativa que possibilitou promover o desenvolvimento profissional e a aprendizagem da docência.

O artigo de Maria de Lurdes Serrazina, denominado O Professor que Ensina Matemática e a sua Formação: uma experiência em Portugal, apresenta o Programa de Formação Contínua em Matemática (PFCM) para professores do $1^{\circ}$ ciclo do Ensino Básico, desenvolvido em Portugal, por iniciativa do Ministério da Educação, e discute o desenvolvimento do conhecimento e da postura da professora Maria, que participou desse programa.

Um artigo aborda uma prática na formação inicial desse profissional: Fazer da Matemática Problema a ser Inventado Inventando Formação, texto de Margareth Aparecida Sacramento Rotondo, apresenta e discute a formação de professores que ensinarão matemática nos anos iniciais do Ensino Fundamental como inquietude e processualidade na experiência, a partir de um evento que ocorreu durante as aulas.

Ainda, Jose Luis Lupiáñez, em artigo de caráter teórico, denominado Competencias del profesor de Educación Primaria, discute as competências que deveriam ser desenvolvidas pelos professores da Educação Primária na Espanha para ensinar matemática.

E, por fim, o artigo intitulado Concepções de Matemática de Alunas-Professoras dos Anos Iniciais, de Reginaldo Fernando Carneiro e Cármen Lúcia Brancaglion Passos, investigou as concepções sobre matemática, seu ensino e sua aprendizagem como alunas-professoras dos anos iniciais do Ensino Fundamental de um curso de Pedagogia a distância. As participantes foram denominadas de alunas-professoras, porque eram alunas do curso de formação e já atuavam como professoras nesse nível de ensino.

Ainda que os autores tenham se ocupado de diferentes questões investigativas, com aportes teóricos diversos, os artigos se aproximam 
e dão sentido às preocupações comuns sobre a formação de professores que ensinam matemática nos anos iniciais do Ensino Fundamental. Os resultados das pesquisas, apresentados nesta seção temática, demonstram que muito tem sido pesquisado com relação a essa tema e que ainda há muitos desafios a serem enfrentados, o que evidencia a necessidade de outras discussões e reflexões sobre ela.

\section{Nota}

1 Declaração assinada por representantes de países da Europa, em 1999, assinada na cidade de Bolonha, que propunha mudanças conjuntas na formação em nível superior para a criação do Espaço Europeu de Ensino Superior - EEES -, que deveriam ser colocadas em prática até o fim da primeira década no novo milênio, ou seja, o ano de 2010.

\section{Referências}

BATISTA, Fábio D.; LANNER, Anna R. A Formação para o Ensino de Matemática nos Currículos de Pedagogia das Instituições de Ensino Superior do Estado de São Paulo: características e abordagens. In: CONGRESSO DE LEITURA DO BRASIL, 16., 2007, Campinas. Anais... Campinas, 2007. P. 1-11. Disponível em: <http://www.alb.com.br>. Acesso em: 10 jul. 2008.

BRASIL. Ministério da Educação. Resolução CNE/CP 1, de 15 de maio de 2006. Brasília, 2006. Disponível em: <http://portal.mec.gov.br/cne/arquivos/pdf/ rcp01_06.pdf>. Acesso em: 19 set. 2011.

CARNEIRO, Reginaldo F.; PASSOS, Cármen L. B., LUPIÁÑEZ, Jose L. A Formação Matemática de Professores da Educação Primária na Espanha: contribuições para a realidade brasileira. In: SEMINÁRIO INTERNACIONAL DE PESQUISA EM EDUCAÇÃO MATEMÁTICA, 5., 2012, Petrópolis. Anais... Petrópolis, 2012. P. 1-20.

CURI, Edda. A Formação Matemática de Professores dos Anos Iniciais do Ensino Fundamental Face às Novas Demandas Brasileiras. Revista Iberoamericana de Educación, Madri, v. 37, n. 5, p. 1-10, 2005. Disponível em: <http://www. rieoei. org/deloslectores/1117Curi.pdf>. Acesso em: 28 jul. 2011.

GATTI, Bernardete A. Formação de Professores no Brasil: características e problemas. Educação e Sociedade, Campinas, v. 31, n. 113, p. 1.355-1.379, 2010. Disponível em: < http://www.scielo.br/pdf/es/v31n113/16.pdf>. Acesso em: 27 jul. 2011.

NACARATO, Adair M. A Formação Matemática das Professoras das Séries Iniciais: a escrita de si como prática de formação. Bolema, Rio Claro, v. 23, n. 37, p. 905-930, 2010.

NACARATO, Adair M.; MENGALI, Brenda L. da Silva; PASSOS, Cármem L. B. A Matemática nos Anos Iniciais do Ensino Fundamental: tecendo fios do ensinar e do aprender. Belo Horizonte: Autêntica, 2009. 158 p.

PASSOS, Cármen L. B. Que Geometria Acontece na Sala de Aula? In: MIZUKAMI, Maria da Graça N.; REALI, Aline M. M. R. Processos Formativos da Docência: conteúdos e práticas. São Carlos: EDUFSCar, 2005. P. 16-44. 
Reginaldo Fernando Carneiro é doutor em Educação e licenciado em Matemática pela Universidade Federal de São Carlos - UFSCar. É professor da Faculdade de Educação e do Programa de Pós-Graduação em Educação Matemática da Universidade Federal de Juiz de Fora - UFJF. Desenvolve pesquisa sobre a formação de professores que ensinam matemática. Coordena o Grupo de Estudos e Pesquisas em Educação Matemática da UFJF. E-mail: reginaldo.carneiro@ufjf.edu.br

Cármen Lúcia Brancaglion Passos é licenciada em Matemática (PUCamp), com mestrado e doutorado em Educação (Unicamp) e pós-doutorado na Universidade de Lisboa. É docente Departamento de Teorias e Práticas Pedagógicas e do Programa de Pós-Graduação em Educação da UFSCar, com pesquisas na área de processos de ensino e de aprendizagem e no campo da formação de professores que ensinam matemática. Coordena o Grupo de Estudos e Pesquisas em Educação Matemática da UFSCar.

E-mail: carmen@ufscar.br 